Author has nothing to disclose with regard to commercial support.

\title{
References
}

1. Pradegan N, Fabozzo A, Gerosa G. Noncoronary sinus replacement in bicuspid valve: the other fate? J Thorac Cardiovasc Surg. 2018;155:525.

2. Milewski RK, Habertheuer A, Bavaria JE, Siki M, Szeto WY, Krause E, et al. Fate of remnant sinuses of Valsalva in patients with bicuspid and trileaflet valves undergoing aortic valve, ascending aorta, and aortic arch replacement. J Thorac Cardiovasc Surg. 2017;154:421-32.

3. Park CB, Greason KL, Suri RM, Michelena HI, Schaff HV, Sundt TM. Fate of nonreplaced sinuses of Valsalva in bicuspid aortic valve disease. J Thorac Cardiovasc Surg. 2011;142:278-84.

4. Peterss S, Bhandari R, Rizzo JA, Fang H, Kuzmik GA, Ziganshin BA, et al. The aortic root: natural history after root-sparing ascending replacement in nonsyndromic aneurysmal patients. Ann Thorac Surg. 2017;103:828-33.

5. Russo CF, Mazzetti S, Garatti A, Ribera E, Milazzo A, Bruschi G, et al. Aortic complications after bicuspid aortic valve replacement: long-term results. Ann Thorac Surg. 2002;74:S1773-6.

6. Ugur M, Schaff HV, Suri RM, Dearani JA, Joyce LD, Greason KL, et al. Late outcome of noncoronary sinus replacement in patients with bicuspid aortic valves and aortopathy. Ann Thorac Surg. 2014;97:1242-6.

https://doi.org/10.1016/j.jtcvs.2017.10.090

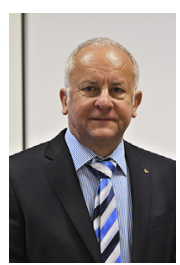

\section{TOTAL ARCH REPLACEMENT FOR REPAIR OF PORCELAIN AORTA}

\section{To the Editor:}

There is no doubt that surgery of a porcelain aorta (PA) is a surgical challenge, and I read the article by Jacob and colleagues ${ }^{1}$ with great interest. The authors cross-sawed the severely calcified ascending aorta with an oscillating saw and replaced its proximal part with a Dacron graft after drilling multiple holes in the calcified distal aorta to allow suturing. Even if the technique described can be an alternative in the elderly, especially when the entire aorta is calcified, I would like to remind the community of our previous publication, ${ }^{2}$ especially because neither Jacob and colleagues ${ }^{1}$ nor the editorial commentary mentioned it in their comments. ${ }^{1,3}$ In this report, we had already indicated that calcification of the proximal aorta most frequently ends just below the left subclavian artery, making a complete aortic arch feasible. ${ }^{2}$ This is especially characteristic for younger patients or those with radiation-related calcifications (Figure 1). The figures provided by Jacob and colleagues ${ }^{1}$ demonstrated exactly the same, namely, that the PA was limited only to the ascending aorta and aortic arch. The authors reasoned their approach with abandonment of a "major aortic surgery," but would a complete arch replacement performed using sophisticated methods of cerebral perfusion have been more complex than a sole ascending aorta replacement for which a deep hypothermia with 45 minutes of circulatory arrest was needed? On the contrary, as

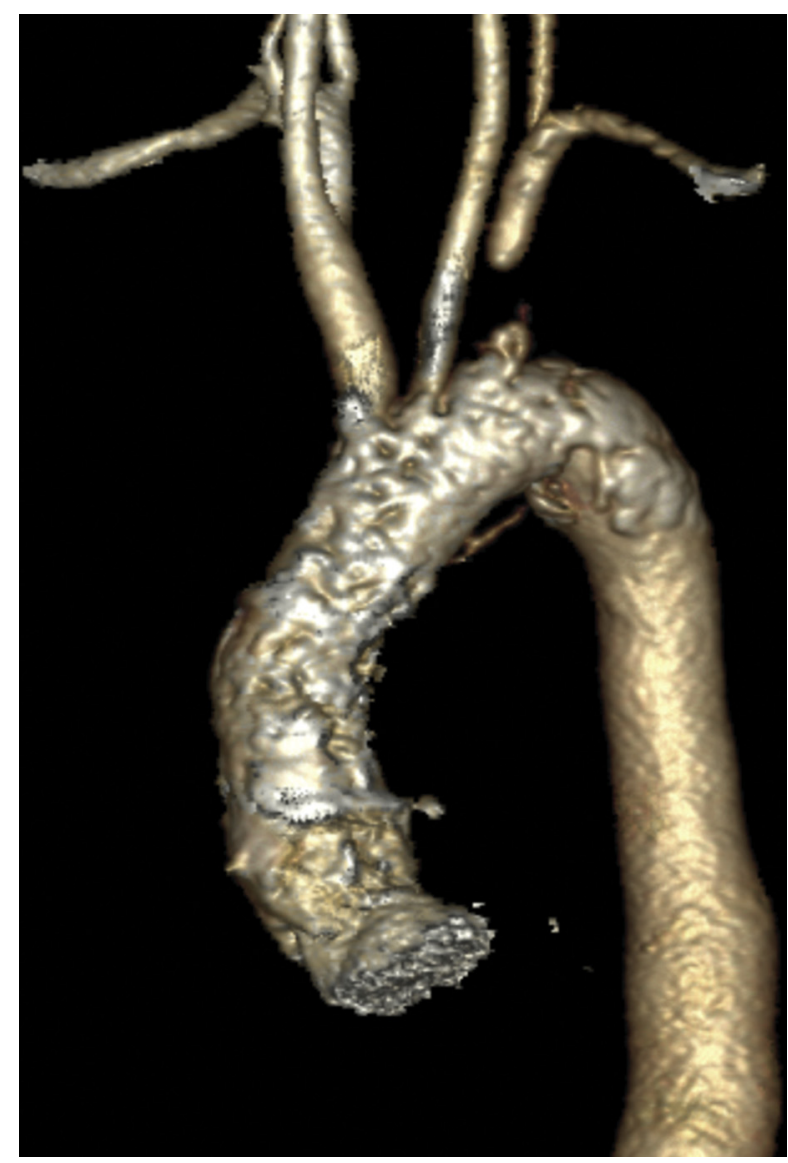

FIGURE 1. Volume rendering technique reconstruction of contrastenhanced computed tomography angiography scans of a 63-year-old male patient demonstrating a typical extent of calcification in proximal PA. The demonstrated patient was one among several who underwent complete root and arch replacement for aortic valve defect combined with a PA, reported in detail by Urbanski and colleagues.

demonstrated in our previous study: A complete arch replacement can be performed under mild-to-moderate hypothermia, without any interruption of cerebral perfusion and any intraluminal manipulations on the supra-aortic arteries (insertion of perfusion catheters can be avoided when unilateral cerebral perfusion is used) and within a total cerebral perfusion time of less than 45 minutes, which is usually necessary for performing 4 anastomoses with a noncalcified arterial wall. ${ }^{2}$ Moreover, the atherosclerosis of the proximal aorta (resulting in a rough inner aortic wall, which is clearly visible in the figures provided by Jacob and colleagues) has been recognized for decades as one of the main sources of cerebral embolism ${ }^{4}$; therefore, a complete arch replacement minimalizes the risk of late neurologic complications, which was zero during a 45-month followup-duration in our study. ${ }^{2}$ I am convinced that surgical therapy in relatively young patients should not only aim for operative survival but also focus on improvement of the late results and the feasibility of any aortic surgeries in 
Author has nothing to disclose with regard to commercial support.

the future. The tendency of homografts to become calcified is well known, and this process can be significantly accelerated by patient-related factors, which have already led to severe calcification of the native aorta. I am wondering, therefore, if the homograft was really the best choice in a 49-year-old patient with a PA, especially because many studies (in the References, only 1 is provided because of space limitation) have demonstrated that the homograft is not a remedy for successful outcomes in complete root replacement due to endocarditis. ${ }^{5}$

Paul P. Urbanski, MD, PhD Cardiovascular Clinic Bad Neustadt Bad Neustadt, Germany

\footnotetext{
References

1. Jacob KA, Rozemeijer R, Den Harder AM, Suyker WJL. Aortic homograft replacement in a patient with a porcelain aorta: a case report. J Thorac Cardiovasc Surg. 2017;154:409-11.

2. Urbanski PP, Raad M, Wagner M, Heinz N, Reents W, Diegeler A. Cardiac surgery in patients with porcelain aorta in the era of transcatheter valve implantation. Eur J Cardiothorac Surg. 2013;44:48-53

3. Helmers M, Atluri P. Passing needle through stone: a novel surgical technique for porcelain aorta. J Thorac Cardiovasc Surg. 2017;154:412-3.

4. Blauth CI, Cosgrove DM, Webb BW, Ratliff NB, Boylan M, Piedmonte MR, et al. Atheroembolism from the ascending aorta. J Thorac Cardiovasc Surg. 1992;103: 1104-12.

5. Jassar AS, Bavaria JE, Szeto WY, Moeller PJ, Maniaci J, Milewski RK, et al. Graft selection for aortic root replacement in complex active endocarditis: does it matter? Ann Thorac Surg. 2012;93:480-8.
}

https://doi.org/10.1016/j.jtcvs.2017.09.088

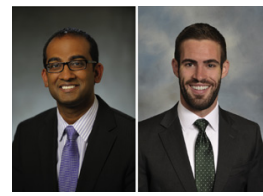

RESPONSE TO: TOTAL ARCH REPLACEMENT FOR REPAIR OF PORCELAIN AORTA

\section{Reply to the Editor:}

In the August issue of the Journal,

Jacob and colleagues ${ }^{1}$ described their use of an aortic homograft for root reconstruction in a 49year-old patient with prosthetic aortic valve endocarditis and porcelain aorta in a case report for which we offered our commentary. ${ }^{2}$ Their technique relied on an oscillating saw for aortotomy and a $0.6-\mathrm{mm}$ orthognathic surgical hand drill for creation of circumferential holes in the distal ascending aorta to facilitate distal anastomosis of a prosthetic graft. ${ }^{1}$ In response to this case report, Urbansky has written a Letter to the Editor in which he offers his critique of the described technique and a cogent argument in favor
Authors have nothing to disclose with regard to commercial support.

of total arch replacement and root replacement with prosthetic graft for this clinical context.

The choice of a prosthetic valved conduit versus a homograft for root replacement in the setting of advanced, destructive aortic endocarditis is still hotly debated. Proponents of homograft reconstruction cite theoretic resistance to infection and availability of mitral leaflet tissue for patching of defects as advantages. ${ }^{3,4}$ However, recent series have demonstrated no statistically significant difference in early survival or reinfection rates between a homograft and a prosthetic valved conduit. ${ }^{5,6}$ Furthermore, homografts are susceptible to structural valve degeneration (SVD), which is primarily a calcific process. Freedom from SVD in aortic homografts has been reported to be only $60 \%$ at 10 years. ${ }^{7}$ Nevertheless, in the setting of prosthetic aortic valve endocarditis, the 2016 American Thoracic Surgery recommendations cite the importance for sufficient debridement and note the advantage of homograft for reconstructing extensive defects but do not make a definitive recommendation for choice of conduit. ${ }^{8}$ As Urbansky points out, a patient with porcelain aorta may indeed be more susceptible to calcific SVD due to host factors. Given the young age of the patient in Jacob and colleagues' case report, ${ }^{1}$ the use of a mechanical valve conduit may decrease the likelihood of a second reoperative aortic surgery, risks and benefits appropriately weighed.

Last, Urbansky argues in favor of total arch replacement in this clinical setting, because the operation can be performed in comparable circulatory arrest times, under mild to moderate hypothermia with antegrade cerebral perfusion. Urbansky also argues that replacing the diseased aorta may decrease the rate of long-term neurologic events. We agree with these points, and given the experience with aortic surgery at our institution, we would have undertaken total arch replacement in this patient as well. Nevertheless, the technique described by Jacob and colleagues ${ }^{1}$ may be useful for surgeons who do not practice at high-volume aortic centers and whose experience with total arch replacement is less robust.

Mark R. Helmers, MD

Pavan Atluri, $M D$

Division of Cardiovascular Surgery

Department of Surgery

University of Pennsylvania

Philadelphia, $\mathrm{Pa}$

\section{References}

1. Jacob KA, Rozemeijer R, Den Harder AM, Suyker WJL. Aortic homograft replacement in a patient with a porcelain aorta: a case report. J Thorac Cardiovasc Surg. 2017; 154:409-11. 